\title{
Determination of the Effect of Sidewall Friction in Reinforced Soil Retaining Wall Experiments
}

\author{
Marek Kulczykowski \\ Institute of Hydro-Engineering, Polish Academy of Sciences, ul. Kościerska 7, 80-953 Gdańsk, Poland, \\ e-mail:marek@ibwpan.gda.pl
}

(Received October 04, 2021; revised November 30, 2021)

\begin{abstract}
A simple approach to estimate sidewall friction in reinforced soil model experiments conducted in parallel-sided test boxes with unlubricated walls is proposed. Analytical solutions are developed for reinforced soil slopes and retaining walls subjected to self-weight or external loading. It turns out that the frictional effect depends on the shape of the failure zone and the value of friction coefficient between soil and a sidewall material. The theoretical predictions were verified in laboratory experiments in a test box with lubricated and unlubricated sidewalls. It was shown that the method can be used to estimate sidewall friction not only under failure conditions, but also under all stages of surcharging prior to failure.
\end{abstract}

Key words: sidewall friction, reinforced soil, model investigations, PIV analysis

\section{Notations}

$a \quad-\quad$ length of failure zone at the top of the RS model in case of uniform surcharge loading,

$a_{P} \quad-$ width of footing model,

$A \quad-$ area of failure zone sliding along the sidewalls,

$H_{E} \quad-\quad$ critical height of the RS model in ideal situation of no sidewall friction,

$H_{E F}$ - experimental critical height of the RS model,

$H_{F} \quad$ - increase of critical height of the RS model caused by sidewall friction,

$K_{0}-$ coefficient of lateral earth pressure,

$L \quad$ - width of test box or length of footing model,

$N_{v} \quad-$ normal pressure force,

(C) 2021 Institute of Hydro-Engineering of the Polish Academy of Sciences. This is an open access article licensed under the Creative Commons Attribution-NonCommercial-NoDerivs License (http://creativecommons.org/licenses/by-nc-nd/4.0/). 
$N_{W} \quad-$ normal component of resultant force of sand weight in tipping experiment,

$P \quad-\quad$ vertical force acting on the footing in case of no sidewall friction,

$P_{E} \quad-\quad$ experimental vertical force acting on the footing,

$P_{H E}$ - force due to the weight the failure block of height $H_{E}$ in case of no sidewall friction,

$P_{H E F}-$ force due to the weight of soil in the failure block of height $H_{E F}$,

$P_{F} \quad-$ total force generated at both sidewalls due to sidewall friction,

$q$ - unit surcharge load in case of no sidewall friction,

$q_{E} \quad-$ experimental unit surcharge load causing failure,

$q_{F} \quad-\quad$ error in surcharge load measurements due to side friction,

$T_{W} \quad-$ tangential component of resultant force of sand weight in tipping experiment,

$W \quad-$ resultant force of sand weight in tipping experiment,

$x, y, z$ - Cartesian coordinates,

$\alpha \quad-$ angle of slip line inclination with the horizontal,

$\beta \quad-$ angle of slope inclination with the horizontal,

$\gamma \quad-$ unit weight of sand,

$\delta \quad-\quad$ friction angle between the soil and the model wall,

$\mu \quad-$ coefficient of sidewall friction,

$\sigma_{v} \quad-$ vertical stress acting to the soil in a direct shear test,

$\sigma_{x} \quad-$ horizontal stress acting normal to the sidewall,

$\sigma_{y} \quad-$ vertical stress,

$\tau_{F} \quad-$ frictional shear stress,

$\phi \quad-$ internal friction angle of sand,

$\omega \quad-$ plate inclination to the horizontal in the tipping experiment.

\section{Introduction}

Reinforced soil (RS) has been used in engineering practice for almost 50 years. In order to better understand the behaviour of reinforced soil structures, a wide range of experimental studies has been carried out. Several geotechnical problems can be investigated by conducting small-scale tests under $1 \mathrm{~g}$ conditions. Such tests with RS models are usually carried out in test tanks in the form of cuboidal, parallel-sided boxes. In these tanks, the friction between the soil and the side walls can significantly affect the experimental results, and therefore should be reduced as much as possible. To reduce this sidewall friction, different methods are employed. The side walls are: (a) made of various kinds of materials with a smooth surface e.g. glass, (b) polished smooth, (c) covered with a low friction sheet e.g. Teflon, polyethylene, or latex membrane, (d) lubricated by oil, gel or grease, (e) coated with lubrication layer consisted of rubber or latex membrane and a thin layer of oil or grease. 
The friction between the soil and sidewall surface is usually tested using a shear box test apparatus. Tatsuoka et al (1984) and Tatsuoka and Haibara (1985) reported the results of a series of direct shear tests between sand and different smooth or lubricated surfaces. Bathurst and Jarrett (1986) and Bathurst and Benjamin (1987) described the shear tests performed in large shear box apparatus to examine the shear-deformation behaviour of sand / polyethylene / plexiglass interface. The results of laboratory tests on friction between cohesive soil and steel were presented by Tsubakihara and Kishida (1993) and Tsubakihara et al (1993). The investigation of sidewall friction for different lubrication methods was described by Fang et al (2004). Also, Zheng at al (2021) demonstrated the effectiveness of several commonly used lubricants in reducing sidewall friction.

In recent years, the use of non-invasive methods in experimental practice has been increasing. Such a non-destructive technique developed for use in geotechnical testing is Particle Image Velocimetry (PIV) (White et al 2003, Stanier et al 2016). This method is now widely employed in soil deformation measurements at different stages of loading. It is an effective tool for measuring soil particle displacements, distribution of volumetric and deviatoric strain, and monitoring the evolution of shear zones (Leśniewska and Wood 2009, Niedostatkiewicz et al 2011). PIV is an image processing technique applying a visualization method. Digital images are captured during tests using a digital high-resolution camera and processed using image analysis software. Therefore, this technique requires the use of a test box with a front wall of good transparency, e.g. made of glass or plexiglass.

However, the application of a lubrication system, e.g., in the form of plastic foil or latex membrane and oil or grease, results in a reduction of sidewall transparency. Such a loss of transparency may reduce the precision and efficiency of the PIV method. If reasonable accuracy in PIV analysis is required, the application of wall lubrication should not be taken into consideration. However, the results reported by Tatsuoka and Haibara (1985) indicated that unlubricated glass or plexiglass sidewall could not be considered as "non-frictional" surfaces. Therefore, in this case, the effect of sidewall friction should be estimated, and taken into account in the analysis of the experimental results.

Bransby and Smith (1975) presented a calculation method developed to estimate the effect of sidewall friction in earth pressure tests on model retaining walls. They found that this effect depends on the roughness of the sidewalls, the angle of internal friction of soil, and on the width of a test box. They also observed the small effects of sidewall friction on plane deformation of soil mass. Bathurst and Benjamin (1987) presented a stability analysis of the block of unreinforced soil to investigate sidewall friction contribution to test retaining walls. The authors concluded that limiting equilibrium wedge analysis gives a correct prediction of wall forces. Jewell (1988) developed a closed-form analytical solution for sidewall friction that takes into account both the soil self-weight and surcharge loading. The analytical results consistent with experimental data indicated a major influence of the sidewall friction. Jayasree et al 
(2012) investigated numerically the influence of sidewall friction in the case of unreinforced models. It was found that this effect is smaller for a wider test box or soil with a greater friction angle.

This paper presents a simple approach to estimate sidewall friction in RS model experiments conducted in parallel-sided test boxes with unlubricated walls. It is shown that the frictional effect depends on the shape of the failure zone observed at the transparent front wall, and the value of friction angle and adhesion coefficient between the sidewall and the backfill. First, commonly used methods of determining the coefficient of sidewall friction are briefly described. Then, analytical solutions developed for both the self-weight and external loading are presented. The theoretical predictions have been verified in two model tests with lubricated and unlubricated sidewalls. Finally, the PIV analysis of the development of the deformation zone in the RS model during loading is presented. The results obtained prove the applicability of the proposed method to all stages of surcharging.

\section{Determination of the Coefficient of Sidewall Friction}

The sidewall friction is a resistance force that prevents soil to slide freely along the surface of the test box wall. The coefficient of sidewall friction $\mu$ indicates how easily soil slides across the wall surface and is defined as a ratio of the resistive force of friction $P_{F}$ and the normal pressure force $N_{v}$. After conversion of the shear and normal loads to respective stresses, the $\mu$ coefficient is expressed by the following equation:

$$
\mu=\frac{P_{F}}{N_{v}}=\frac{\tau_{F}}{\sigma_{v}}
$$

where $\tau_{F}$ is bond shear stress and $\sigma_{v}$ is stress acting normal to the sidewall. The sidewall friction can be also described by an apparent angle of sidewall friction $\delta$, defined by the slope angle of shear stress - normal stress characteristic (see Figure 1):

$$
\delta=\tan ^{-1}\left(\frac{\tau_{F}}{\sigma_{v}}\right)=\tan ^{-1}(\mu) .
$$

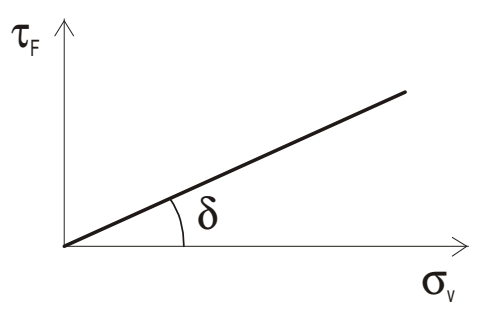

Fig. 1. Shear stress - normal stress characteristic

The angle of sidewall friction $\delta$ can be determined in the laboratory by the direct shear test. However, for cohesionless sand, this angle $\delta$ can be easily determined 
in a so-called tipping experiment, similar to that described by Lambe and Whitman (1979) in the case of stability of a slope. In the tipping experiment, the stability of a sand layer resting on the surface of an inclined plate made of the same material as the sidewall is investigated. During the test, an angle of the plate inclination to the horizontal, $\omega$ is gradually increased to the limit angle $\omega=\omega_{\max }$ at which the full shear resistance is mobilized (Figure 2).

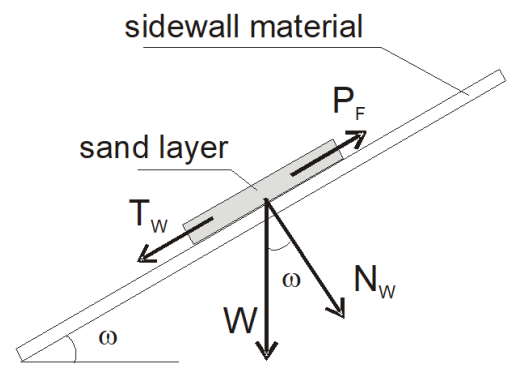

Fig. 2. Analysis of equilibrium of sand layer on inclined sidewall material

When the soil mass remains in limit equilibrium, the following relations hold:

$$
\begin{gathered}
P_{F}=N_{W} \tan \delta, \\
P_{F}=N_{W} \tan \omega_{\max },
\end{gathered}
$$

and

$$
P_{F}=T_{W},
$$

where $N_{W}$ is the normal component of the resultant force of sand weight $W, P_{F}$ is a force generated due to sidewall friction, and $T_{W}$ is the tangential component of $W$. On substituting equations (3) and (4) into equation (5) one obtains:

$$
\delta=\omega_{\max } .
$$

Therefore, once sliding occurs, the plate will have an average inclination $\omega$ which is roughly equal to the angle of sidewall friction $\delta$. It should be noted that the results presented by Tatsuoka and Haibara (1985) indicate, that the angle of friction between sand and smooth platen surfaces is nearly independent of the normal stress level, therefore it can be also regarded as independent of the height of the sand layer.

However, the most suitable laboratory test is to characterize the interaction between two materials is a direct shear test. The conventional direct shear test device is built of two half boxes with the upper one fixed rigidly. The sample of sidewall material is placed inside the lower half box, and the upper half box is filled with soil. The size of tested samples ranges between $50 \mathrm{~mm}$ and $75 \mathrm{~mm}$ due to the inside dimensions of the box, and they are either round or square in shape. The lower half box is seated on low friction bearings to move with minimum resistance. The vertical 
load is applied to the soil through a loading cap and the horizontal shear loading is applied to the lower box. The principle of the shear box test is illustrated in Figure 3 .

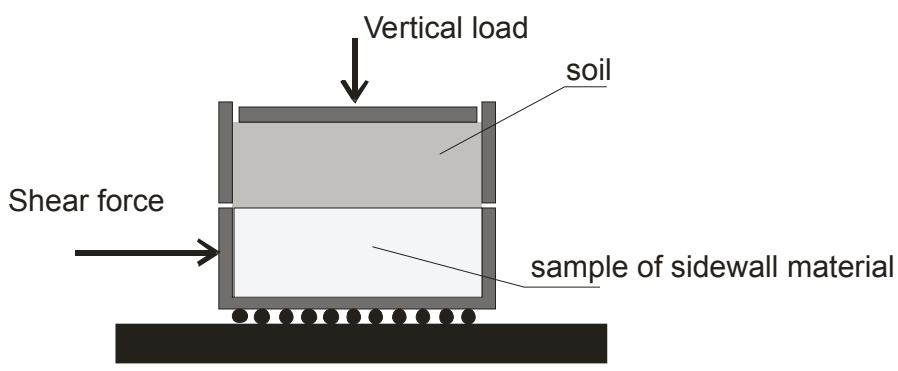

Fig. 3. Schematic view of direct shear test device

The conventional direct shear test device can only hold a small size specimen, therefore to test larger samples the Large Shear Box (LSB) apparatus should be used. Such a device allows overcoming some limitations in terms of sample preparation and reproducing real conditions. The principle of the Large Shear Box is similar to the conventional shear box apparatus. LSB is capable of carrying out tests on soil specimens up to $305 \mathrm{~mm}$ square. In this device, the lower box is larger than the upper box, and is usually placed on the rigid platform running on low friction guides (Figure 4).

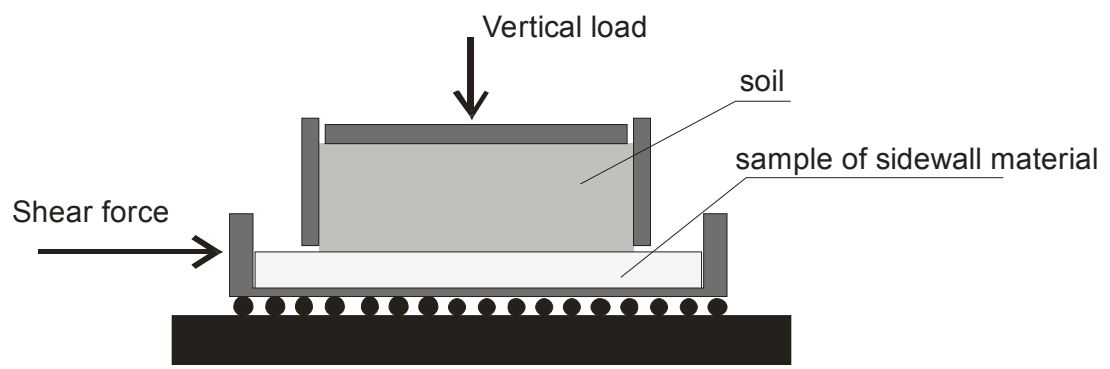

Fig. 4. Schematic view of large direct shear test apparatus

The direct shear test is also performed to determine the friction resistance between the soil and lubricated sidewalls materials. Various shear-type apparatuses have been developed to study the frictional behaviour between soil and smooth or lubricated surfaces. Yoshimi and Kishida (1981) describe a ring torsion apparatus used to evaluate friction between dry sand and a steel surface. The shear box device with a cylindrical container is described by Tatsuoka et al (1984) and Tatsuoka and Haibara (1985). Large scale direct shear test $(1 \mathrm{~m} \times 1 \mathrm{~m})$ is reported by Bathurst and Jarrett (1986). Tsubakihara et al (1993) describe a simple shear-type apparatus that additionally allows for the tangential displacement of the sample. Fang et al (2004) present a new sliding block testing device for measuring the friction at the interface between soil and 
different materials at low-stress conditions. Large scale direct shear device designed to perform load and displacement controlled cyclic tests is described by Vieira et al (2013).

\section{Estimation of the Effect of Sidewall Friction in RS Model Test}

Generally, the height of a structure or a magnitude of external load required to cause the failure of the RS model in the test box consist of two components: (a) a component necessary to fail the model, and (b) a component necessary to slide the failure zone along the sidewalls of the test box (see Bransby and Smith 1975). A schematic diagram of the test configuration, in case of reinforced slope loaded by a footing, is presented in Figure 5. When the slope failure is induced, the deformation zone OAB is formed within the massive of reinforced soil and is sliding along the sidewalls of the test box (Fig 5a). In the case of unlubricated sidewalls, the experimental failure load may be significantly increased by the effect of friction between the sidewall and the sliding failed block of reinforced soil (Fig. 5b). The magnitude of this frictional component should be estimated and included in the analysis of experimental measurements.

a)

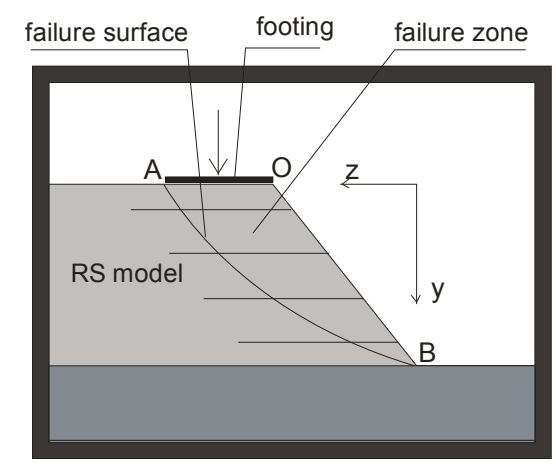

b)

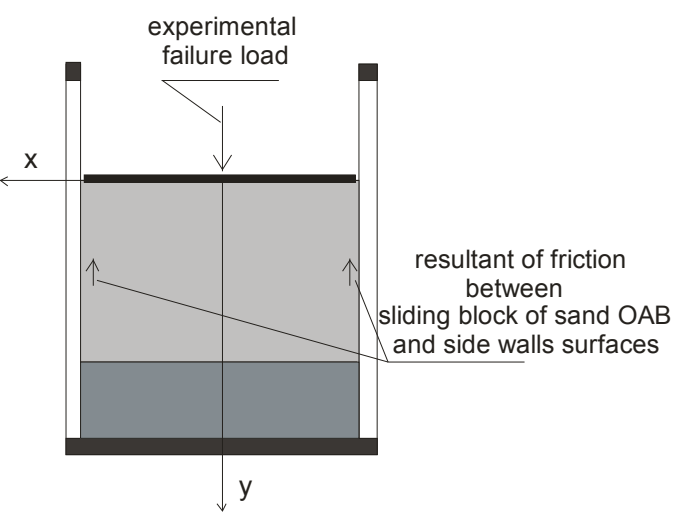

Fig. 5. a) Failure of RS model; b) Cross section of the test box 01

In this section, a simple method of such estimation is described and applied to typical situations. The analysis is performed on the following assumptions:

1. The test is conducted under a plane strain condition in a parallel-sided test box with transparent side walls.

2. Both front and back walls are made of the same material.

3. The shape of the failure zone at the front side wall is recorded.

4. The values of the angle of sidewall friction $\delta$ and adhesion factor $c_{\delta}$ are given.

5. The stress distribution in RS structure is represented by a simple statically admissible stress field for determining the so-called critical height or critical external load of RS structure (Sawicki 2000, pp. 114-118). 
6. The coefficient of lateral earth pressure, $K_{0}$, is determined from Jaky's equation (Lambe and Whitman 1979, p. 127).

7. In the case of footing loading, the length of the footing is equal to the width of the test box in order to maintain the plane strain conditions, and the friction between the sidewalls and the footing edges is neglected.

\subsection{The Model of RS Slope Subjected to Self-weight Loading}

The commonly observed slope failure mode, depending on sliding of the deformation zone $\mathrm{OAB}$ along the failure surface $\mathrm{AB}$ passing through the toe of the structure, is presented schematically in Figure 6 . The $H_{E F}$ denote the experimental critical height of the RS model, defined as the height at which the structure will collapse due to its self-weight. The experimental slip line $\mathrm{AB}$ is described by function $z=f(y)$ obtained by the conventional curve fitting method. $H_{F}$ is the increase of HEF caused by sidewall friction, and $H_{E}$ is the critical height in the ideal situation of no sidewall friction.

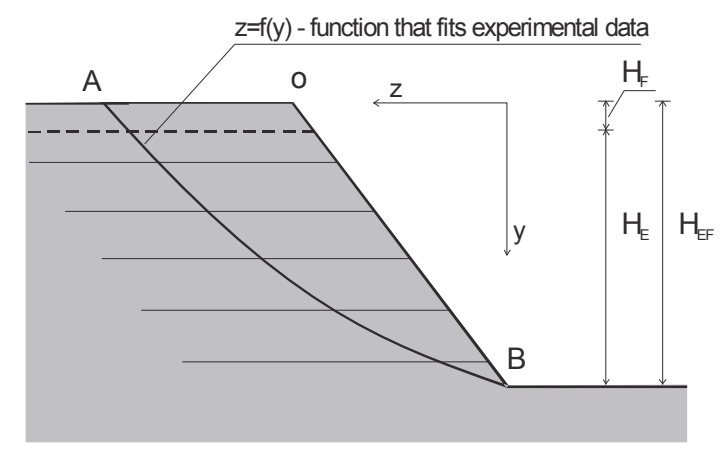

Fig. 6. Failure of RS model subject to self-weight loading

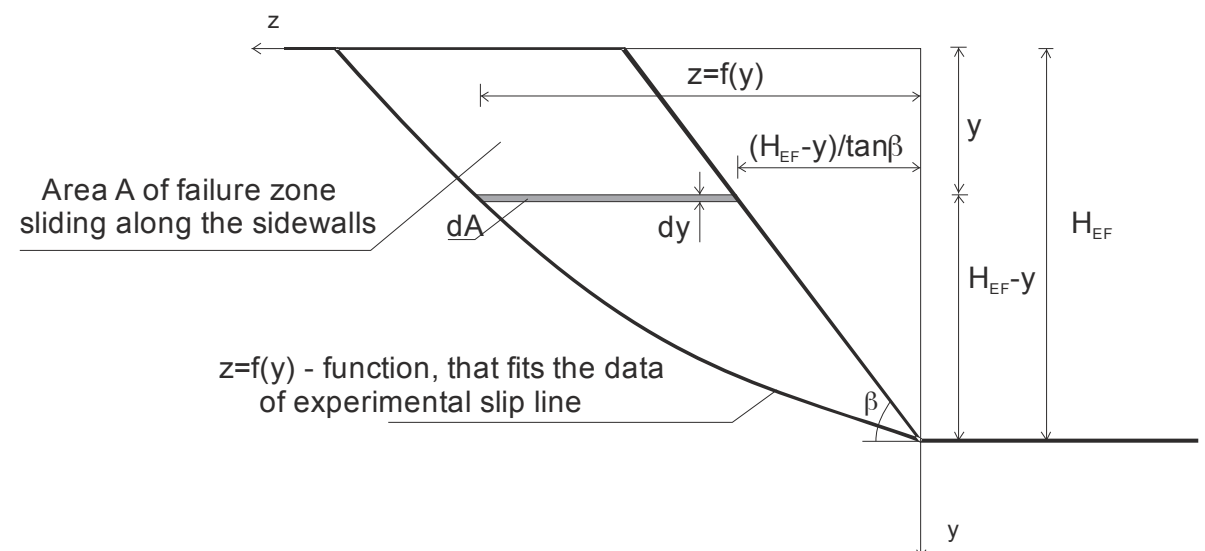

Fig. 7. RS slope notation 
Let us denote by $P_{H F}$ the total force generated at both sidewalls due to sidewall friction. The area of failure zone sliding along the sidewalls is denoted as $A$. Part of this force, $d P_{F}$, generated at the depth $y$ at $d A$ area (see Figure 7) can be expressed as:

$$
d P_{F}=\tau_{F} d A
$$

where $\tau_{F}$ is tangential stress acting on the sidewall, and $d A$ is given by the following formula:

$$
d A=\left[f(y)-\left(H_{E F}-y\right) \frac{1}{\tan \beta}\right] d y,
$$

where $\beta$ is an angle of slope inclination with the horizontal.

The tangential shearing stress $\tau_{F}$ exerted on the sidewall is given by the well-known formula:

$$
\tau_{F}=\sigma_{x} \tan \delta+c_{\delta},
$$

where $\sigma_{x}$ is the horizontal stress component acting normally to the sidewall

$$
\sigma_{x}=K_{0} \sigma_{y},
$$

and $\sigma_{y}$ is the vertical stress component at the depth $y$, given by

$$
\sigma_{y}=\gamma y,
$$

where $K_{0}$ is a coefficient of lateral earth pressure, and $\gamma$ is unit weight of soil.

According to the general assumption, the coefficient $K_{0}$ is determined from Jaky's equation:

$$
K_{0}=(1-\sin \phi),
$$

where $\phi$ is an angle of soil internal friction.

Substitution of equations (8) to (12) into equation (7) leads to the following formula:

$$
d P_{F}=\left[(1-\sin \phi) \gamma y \tan \delta+c_{\delta}\right]\left[f(y)-\left(H_{E F}-y\right) \frac{1}{\tan \beta}\right] d y .
$$

Integration of equation (13) over both sidewalls gives a total sidewall friction force:

$$
P_{F}=2 \int_{0}^{H_{E F}}\left[(1-\sin \phi) \gamma y \tan \delta+c_{\delta}\right]\left[f(y)-\left(H_{E F}-y\right) \frac{1}{\tan \beta}\right] d y .
$$

On the other hand, the friction force $P_{F}$ can be determined from the formula:

$$
P_{F}=P_{H E F}-P_{H E},
$$

where $P_{H E F}$ is a force due to the weight of soil in the failure block of height $H_{E F}$, and $P_{H E}$ is a force due to the weight of the failure block of height $H_{E}$ in case of no sidewall friction. 
The forces $P_{H E F}$ and $P_{H E}$ can be expressed by

$$
\begin{aligned}
P_{H E F} & =\int_{0}^{H_{E F}} L d A=\int_{0}^{H_{E F}} L\left[f(y)-\left(H_{E F}-y\right) \frac{1}{\tan \beta}\right] d y, \\
P_{H E} & =\int_{0}^{H_{E}} L d A=\int_{0}^{H_{E}} L\left[f(y)-\left(H_{E}-y\right) \frac{1}{\tan \beta}\right] d y,
\end{aligned}
$$

where $L$ is the width of the test box.

The values of $P_{F}$ and $P_{H E F}$ can be calculated from equations (14) and (16). The value of $H_{E}$, which is lower than that of $H_{E F}$, can be determined by the trial and error method by applying the following formula:

$$
\int_{0}^{H_{E}} L\left[f(y)-\left(H_{E}-y\right) \frac{1}{\tan \beta}\right] d y=P_{H E F}-P_{H F} .
$$

Finally, the increase in experimental critical height due to sidewall friction can be calculated as the difference in height between $H_{E F}$ and $H_{E}$ :

$$
H_{F}=H_{E F}-H_{E} \text {. }
$$

If the experimental failure surface can be approximated by a planar surface, the above relations are simplified, and then the values of $H_{F}$ and $H_{E}$ can be determined analytically. In this case, the function $z=f(y)$ is given

$$
z=\left(H_{E F}-y\right) \frac{1}{\tan \alpha},
$$

where $\alpha$ is an angle of slip line inclination with the horizontal (Figure 8a), and equations (8), (14), (16) and (17) become

$$
\begin{gathered}
d A=(\cot \alpha-\cot \beta)\left(H_{E F}-y\right) d y, \\
P_{F}=(\cot \alpha-\cot \beta) H_{E F}^{2}\left[\frac{1}{3} H_{E F}(1-\sin \phi) \gamma \tan \delta+c_{\delta}\right], \\
P_{H E F}=L \gamma(\cot \alpha-\cot \beta) \frac{H_{E F}^{2}}{2}, \\
P_{H E}=L \gamma(\cot \alpha-\cot \beta) \frac{H_{E}^{2}}{2} .
\end{gathered}
$$

The values of $H_{E}$ and $H_{F}$ are defined by the following formulae:

$$
H_{E}=H_{E F}=\sqrt{1-\frac{2}{L \gamma}\left[\frac{\tan \delta}{3}(1-\sin \phi) \gamma H_{E F}+c_{\gamma}\right]} .
$$


a)

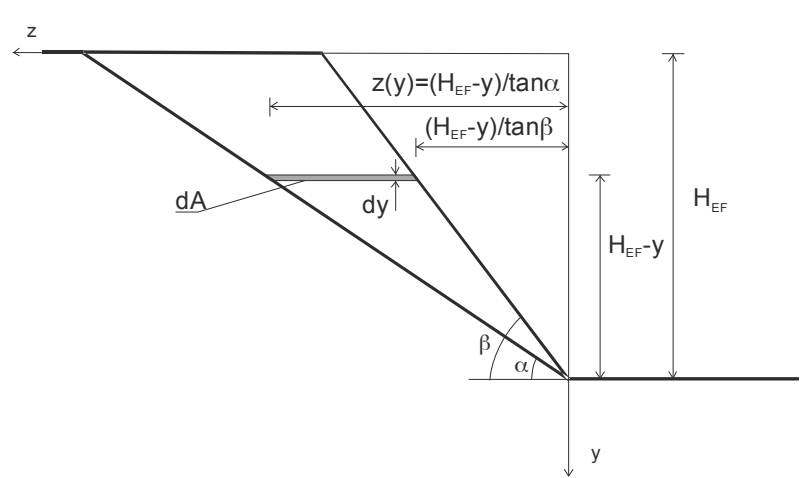

b)

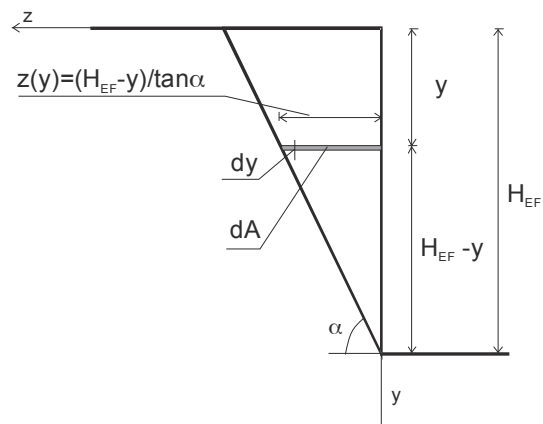

Fig. 8. Notation in case of planar failure surface: a) RS slope with the inclined front face, b) RS vertical wall

$$
H_{F}=H_{E F}=\left\{1-\sqrt{1-\frac{2}{L \gamma}\left[\frac{\tan \delta}{3}(1-\sin \phi) \gamma H_{E F}+c_{\gamma}\right]}\right\}
$$

The above formulae can be also used for the case of the vertical RS wall model, since they are independent of the angle of slope inclination $\beta$.

\subsection{The Model of Vertical RS Wall Subjected to Uniform Surcharge Loading}

Consider now the case of the model of vertical RS retaining wall with surcharge which is uniformly distributed over the whole crest area, as presented schematically in Figure 9. The $H$ is the height of the wall, $q_{E}$ is the unit surcharge load on the model wall recorded at failure, and $z=(y)$ is the function describing the shape of the experimental slip line, $a$ is the length of the failure zone at the crest.

In the case considered, equations (8) and (11) take the forms:

$$
\begin{gathered}
d A=f(y) d y, \\
\sigma_{y}=\gamma y+q_{E} .
\end{gathered}
$$




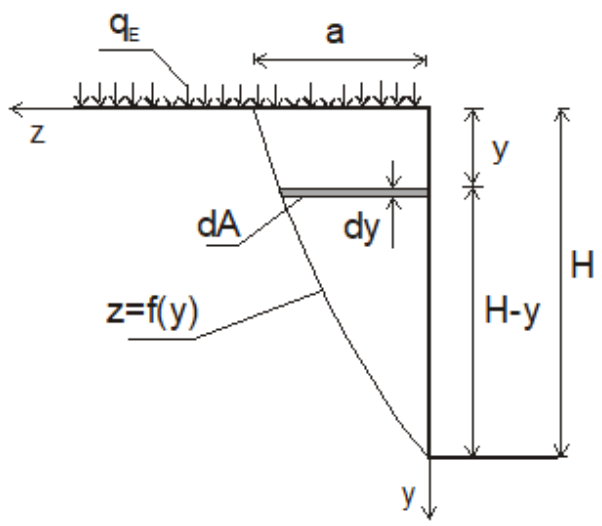

Fig. 9. RS wall subjected to uniform surcharge loading

The tangential stress component acting on the sidewall is given by

$$
\tau_{F}=(1-\sin \phi)\left(\gamma y+q_{E}\right) \tan \delta+c_{\delta} .
$$

Substitution of equations (27) and (29) into (7), and integration over both sidewalls, gives the sidewall friction force in the form

$$
P_{F}=2 \int_{0}^{H}\left[(1-\sin \phi)\left(\gamma y+q_{E}\right) \tan \delta+c_{\delta}\right] f(y) d y .
$$

The magnitude of error in surcharge load measurements due to side friction $q_{F}$ is given by

$$
q_{F}=\frac{P_{F}}{a L} .
$$

Finally, the unit surcharge load $q$ causing failure in case of no sidewall friction can be calculated from

$$
q=q_{E}-q_{F} .
$$

In case of a planar failure surface inclined to the horizontal at an angle $\alpha$ (Figure 10), equations (30) to (32) take the forms:

$$
\begin{gathered}
P_{F}=H^{2} \cot \alpha\left[\tan \delta(1-\sin \phi)\left(\frac{\gamma H}{3}+q_{E}\right)+c_{\delta}\right], \\
q_{F}=\frac{H}{L}\left[\tan \delta(1-\sin \phi)\left(\frac{\gamma H}{3}+q_{E}\right)+c_{\delta}\right], \\
q=q_{E}\left[1-\frac{H}{L} \tan \delta(1-\sin \phi)\right]-\left[(1-\sin \phi) \frac{\gamma H}{3} \tan \delta+c_{\delta}\right] .
\end{gathered}
$$




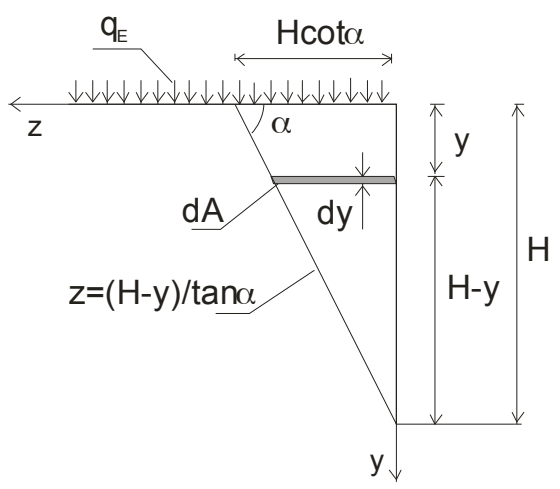

Fig. 10. Case of a planar failure surface

\subsection{The Model of Vertical RS Wall Subjected to Footing Loading}

Next consider the model of vertical RS retaining wall loaded with a strip footing placed on the top, close to the wall facing (Figure 11).

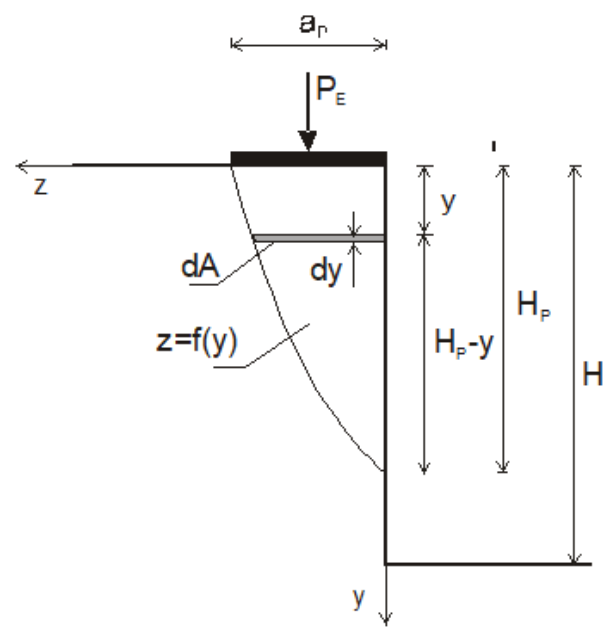

Fig. 11. RS wall subjected to footing loading

In this case, the height of deformation zone $H_{P}$ depends on the footing width $a_{P}$. It is assumed that extent of the failure zone does not exceed the model height $\left(H_{P} \leq H\right)$. The vertical loading force $P_{E}$ is applied to the centre of footing. The length of the strip footing model is equal to the width $L$ of the test box. For convenience, the soil bearing pressure $p_{E}$ beneath the footing is assumed to be uniform:

$$
p_{E}=\frac{P_{E}}{a_{P} L} .
$$


In this case, equation (11) becomes

$$
\sigma_{y}=\gamma y+\frac{P_{E}}{a_{P} L} .
$$

The sidewall friction force is given by

$$
P_{F}=2 \int_{0}^{H_{P}}\left[(1-\sin \phi)\left(\gamma y+\frac{P_{E}}{a_{P} L}\right) \tan \delta+c_{\delta}\right] f(y) d y,
$$

and the loading force $P$ causing failure in case of no sidewall friction can be calculated from:

$$
P=P_{E}-P_{F} .
$$

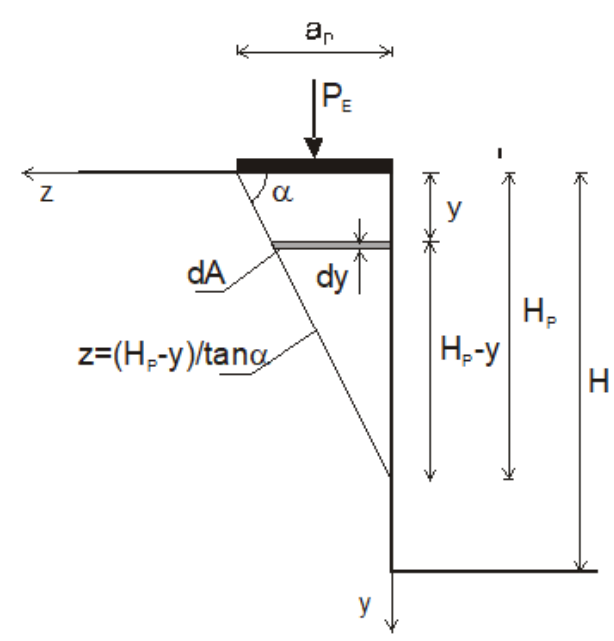

Fig. 12. Planar failure surface in case of footing loading

If the experimental failure surface can be assumed as a plane slip surface (Figure 12), equations (38) and (39) take the forms:

$$
\begin{gathered}
P_{F}=a_{P}^{2} \tan \alpha\left[\tan \delta(1-\sin \phi)\left(\frac{a_{P} \gamma \tan \alpha}{3}+\frac{P_{E}}{a_{P} L}\right)+c_{\delta}\right], \\
P=P_{E}\left[1-\frac{a_{P}}{L} \tan \delta \tan \alpha(1-\sin \phi)\right]- \\
-a_{P}^{2} \tan \alpha\left[\frac{1}{3}(1-\sin \phi) a_{P} \gamma \tan \delta \tan \alpha+c_{\delta}\right] .
\end{gathered}
$$

\section{Experimental Verification}

Two laboratory tests were performed to evaluate the accuracy of the proposed analytical approach with a model of the vertical RS retaining wall subjected to footing 
loading. Both tests were carried out in the same rigid test box with the sidewalls made of glass. One test was conducted in the test box with unlubricated sidewalls, whereas the other was performed with sidewalls coated with a lubrication layer. The inside dimensions of the test box were: $66 \mathrm{~cm}$ (long) $\times 50 \mathrm{~cm}$ (high) $\times 26 \mathrm{~cm}$ (wide), and the dimensions of the RS model were: $30 \mathrm{~cm}$ (high) $\times 50 \mathrm{~cm}$ (long) $\times 26 \mathrm{~cm}$ (wide). The model was constructed in 6 layers of sand and the strip reinforcement with $5 \mathrm{~cm}$ vertical spacing (Figure 13).

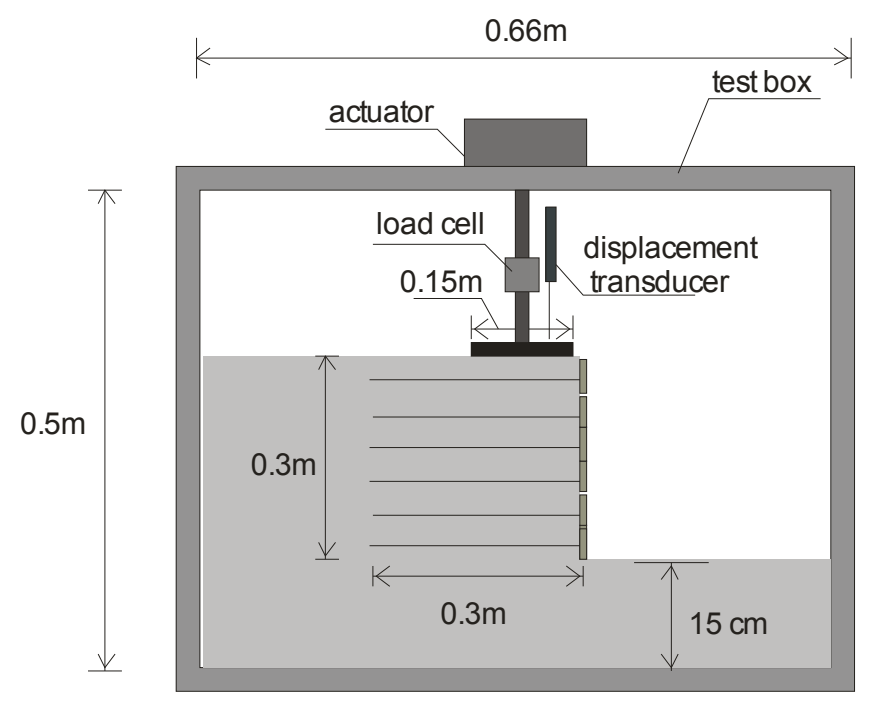

Fig. 13. The view of the test setup

Dry silicon cohesionless sand with the unit weight of $17 \times 10^{3} \mathrm{~N} / \mathrm{m}^{3}$ and an angle of internal friction $31.3^{\circ}$ was used in the tests. The aluminum foil characterized by the tensile strength $44 \times 10^{3} \mathrm{kN} / \mathrm{m}^{2}$ was used as the reinforcement. The reinforcement in each layer consisted of three fabric strips with a centre-to-centre spacing of 8.7 $\mathrm{cm}$. Each strip was $30 \mathrm{~cm}$ long, $5 \mathrm{~cm}$ wide and $18 \times 10^{-6} \mathrm{~m}$ thick. The strips were connected to cardboard elements used as wall facings $5 \mathrm{~cm}$ high and $26 \mathrm{~cm}$ long (Figure 14). The model footing used in experiments was made of a $1.5 \mathrm{~cm}$ thick rigid steel plate, $26 \mathrm{~cm}$ long and $15 \mathrm{~cm}$ wide.

The angle of sidewall friction between sand and unlubricated glass wall, determined in the tipping experiment, was $\delta=25^{\circ}$. In the experiment with sidewalls lubrication, both sidewalls were coated with a double layer of thin polyethylene sheeting lubricated with silicon grease.

The sand was placed in the test box using a pluviation technique. First, the layer of sand foundation of $15 \mathrm{~cm}$ deep was placed in the test box. Then, the model was constructed layer by layer from bottom to top at temporary support in the form of a wooden element. This support was removed after the structure was completed. The 


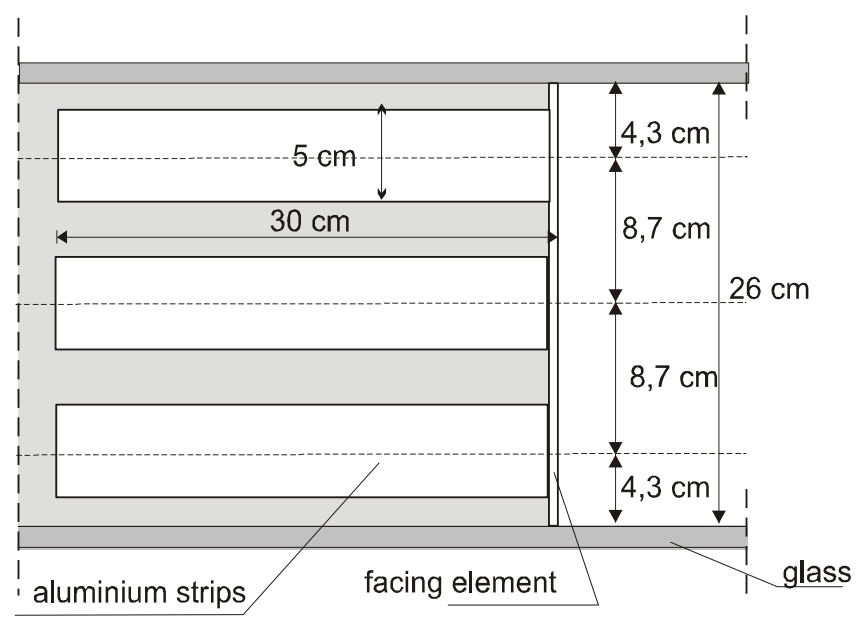

Fig. 14. Arrangement of reinforcing strips

load was then applied through a footing pushed downwards with the constant displacement rate of $0.33 \mathrm{~cm} / \mathrm{min}$. The model was loaded until a failure condition was reached. The footing load and footing displacement were measured continuously. The shape of the deformation zone was observed and recorded using a digital photo camera. After the test completion, the failure surface was additionally determined by the location of the points of tensile rupture of reinforcement.

In both experiments, the same mechanisms of failure were recorded, characterized by slippage of the failure wedge beneath the footing, across the near-planar surface (Figure 15). The height of both deformation zones, similar in shape to a triangle, was $27 \mathrm{~cm}$.

a)

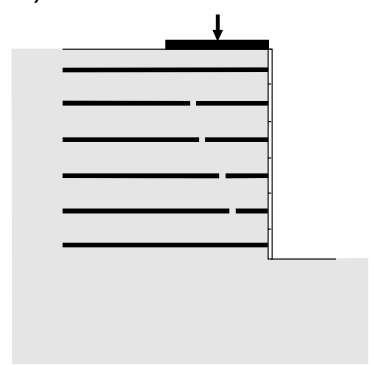

b)

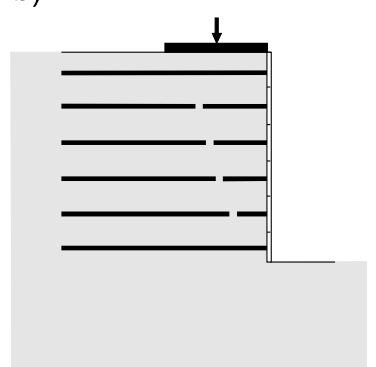

Fig. 15. Triangular failure zone of RS model. Test box with a) unlubricated sidewalls, b) sidewalls with lubrication

After testing, the reinforcement strips were removed from the RS mass and all, except the lowest and highest layers of reinforcement, were found to have ruptured. The locations of the rupture lines in the reinforcement agreed with the slip surface in the soil mass. 
In the experiment with unlubricated sidewalls, the model failed at an applied vertical load of $1.31 \mathrm{kN}$, about $27 \%$ higher than that in the experiment with lubricant application (failure load $=1.03 \mathrm{kN}$ ). The vertical displacement of footing at failure was the same in both experiments (displacement equal to $9 \mathrm{~mm}$ ). As expected, the presence of the lubrication layer had significantly decreased the experimental failure load. However, the shape and size of the failure zone and footing displacement were similar in both experiments. This confirmed the results reported by Bransby and Smith (1975), who observed the small effects of sidewall friction on plane deformation of soil mass.

To check the accuracy of the proposed method of estimation of sidewall friction, the experimental results are compared with theoretical predictions. The sidewall friction force $P_{F}$ and force $P$ causing failure in case of no sidewall friction have been calculated for the following experimental data: $P_{E}=1.31 \times 10^{3} \mathrm{~N}$, $P_{F}=\left(1.31 \times 10^{3}-1.03 \times 10^{3}\right)=0.28 \times 10^{3} \mathrm{~N}, H_{P}=0.27 \mathrm{~m}, a_{P}=0.15 \mathrm{~m}, L=0.26$ $\mathrm{m}, c_{\delta}=0 \mathrm{~N} / \mathrm{m}^{2}, \alpha=\tan ^{-1}\left(a_{P} / H_{P}\right)=29^{\circ}, \delta=25^{\circ}, \phi=31.3^{\circ}, \gamma=17 \times 10^{3} \mathrm{~N} / \mathrm{m}^{3}$. With these parameters, equations (40) and (41) have given $P_{F}=0.30 \times 10^{3} \mathrm{~N}$ and $P=1.01 \times 10^{3} \mathrm{~N}$, respectively. Thus, the theoretical prediction is close to the experimental results which indicate that the simple analytical method for sidewall friction estimation proposed in this paper yields reasonably accurate results.

\section{Applicability of the Method to the Whole Loading Process}

The method described in Section 3 concerns the final stage of loading when the RS model had reached a failure state and the soil in the failure zone began sliding along the sidewalls. At this stage, the failure mechanism is fully developed and the shape of the deformation zone can be easily observed and recorded at the transparent sidewall. However, at the initial stages of loading, the displacements of soil particles are very small and the visual identification of the shape of the deformation zone is most often impossible.

Therefore, to verify the applicability of the method to stages preceding the initiation of failure, Particle Image Velocimetry (PIV) technique was employed. The PIV was used for monitoring the evolution of soil particle displacements zone in the model of RS retaining wall subjected to continuous loading up to failure.

The experiment was conducted in a test box with transparent glass sidewalls. A model of a vertical RS retaining wall was constructed in 10 layers of sand and reinforcement with $5 \mathrm{~cm}$ vertical spacing. The dimensions of the model were: $50 \mathrm{~cm}$ (high) $\times 60 \mathrm{~cm}$ (long) $\times 37 \mathrm{~cm}$ (wide). Dry cohesionless sand was used in the tests. The reinforcement in each layer consisted of three aluminum strips connected to timber elements used as wall facings. The RS model was subjected to footing loading (Figure 16). The model of footing was made of a $2.5 \mathrm{~cm}$ thick rigid steel and was 29 $\mathrm{cm}$ wide and $37 \mathrm{~cm}$ long. 


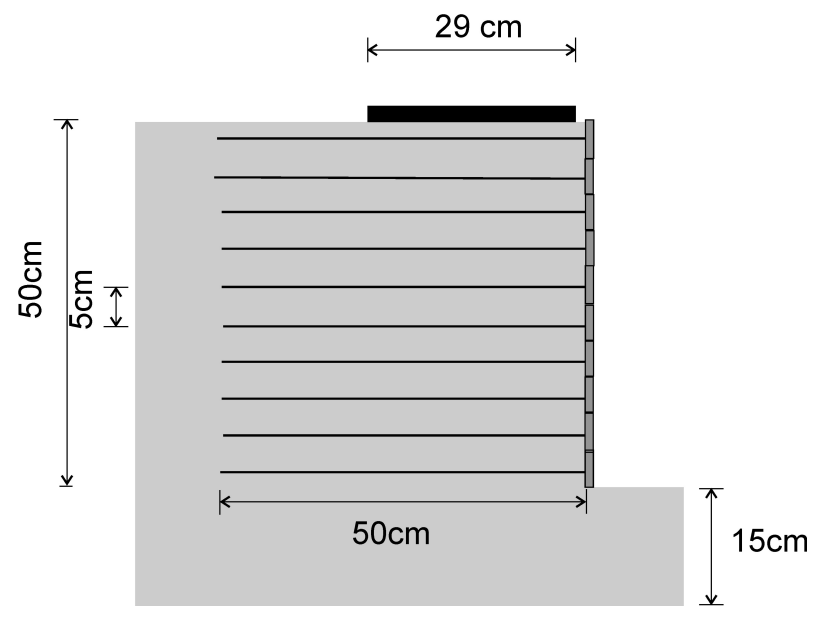

Fig. 16. Test configuration

The vertical load was applied continuously until a failure state was reached. The experiment was recorded using a camera. To localize soil deformation and identify the evolution of the deformation zone, the camera images were taken at defined loading steps. Digital images were processed using particle image velocimetry (PIV) software.

The images captured at subsequent stages of loading and the corresponding results of PIV analysis are presented in Table 1.

The results of PIV analysis show that the deformation zone has been developed beneath footing during the whole loading process. The shape of this zone is similar at all loading stages. On the other hand, the results reported by Bathurst and Benjamin (1987) indicate that full sidewall friction capacity is mobilized after relatively little deformation. It can be concluded that by taking into account the above-mentioned findings, the method presented in this paper can be applied to estimate the effect of sidewall friction not only at the failure state, but also during the entire process of loading.

\section{Concluding Remarks}

In recent years, the use of PIV method in experimental practice has been increasing. However, this technique requires the use of a test box with a front wall of good transparency. Therefore, if accuracy in PIV analysis is required, the application of sidewall lubrication should not be considered, as it results in a reduction of transparency.

However, unlubricated sidewalls cannot be considered as "non-frictional" surfaces, and in this case the effect of sidewall friction should be estimated, and taken into account in the analysis of the experimental results. In this paper, the simple theoretical approach to estimate sidewall friction in RS model experiments conducted in parallel-sided test boxes with unlubricated walls is presented. It has turned out that the frictional effect depends on the shape of the failure zone registered at the transparent 
Table 1. Images captured during experiment and displacements of soil particles

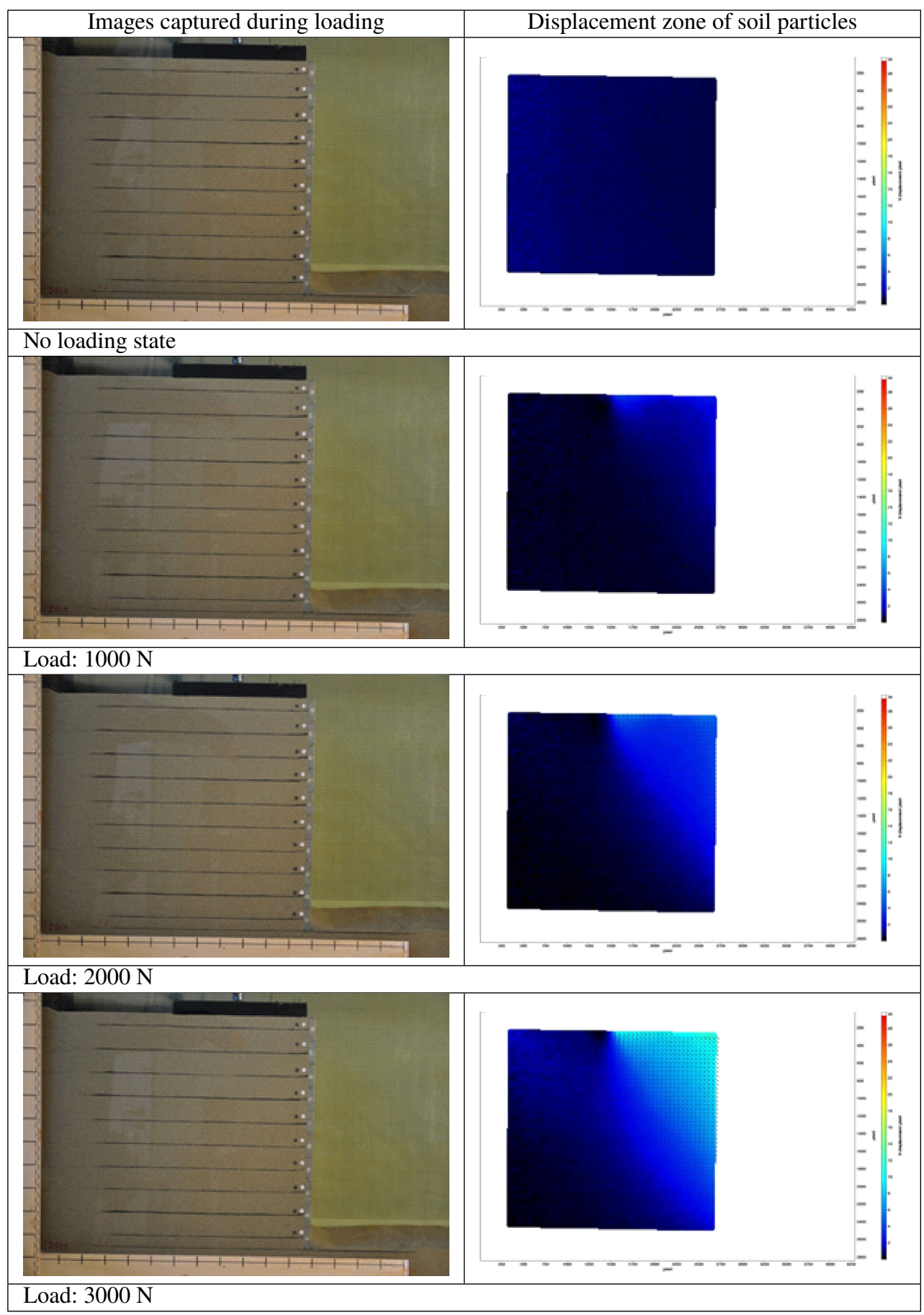


Table 1. (continued)
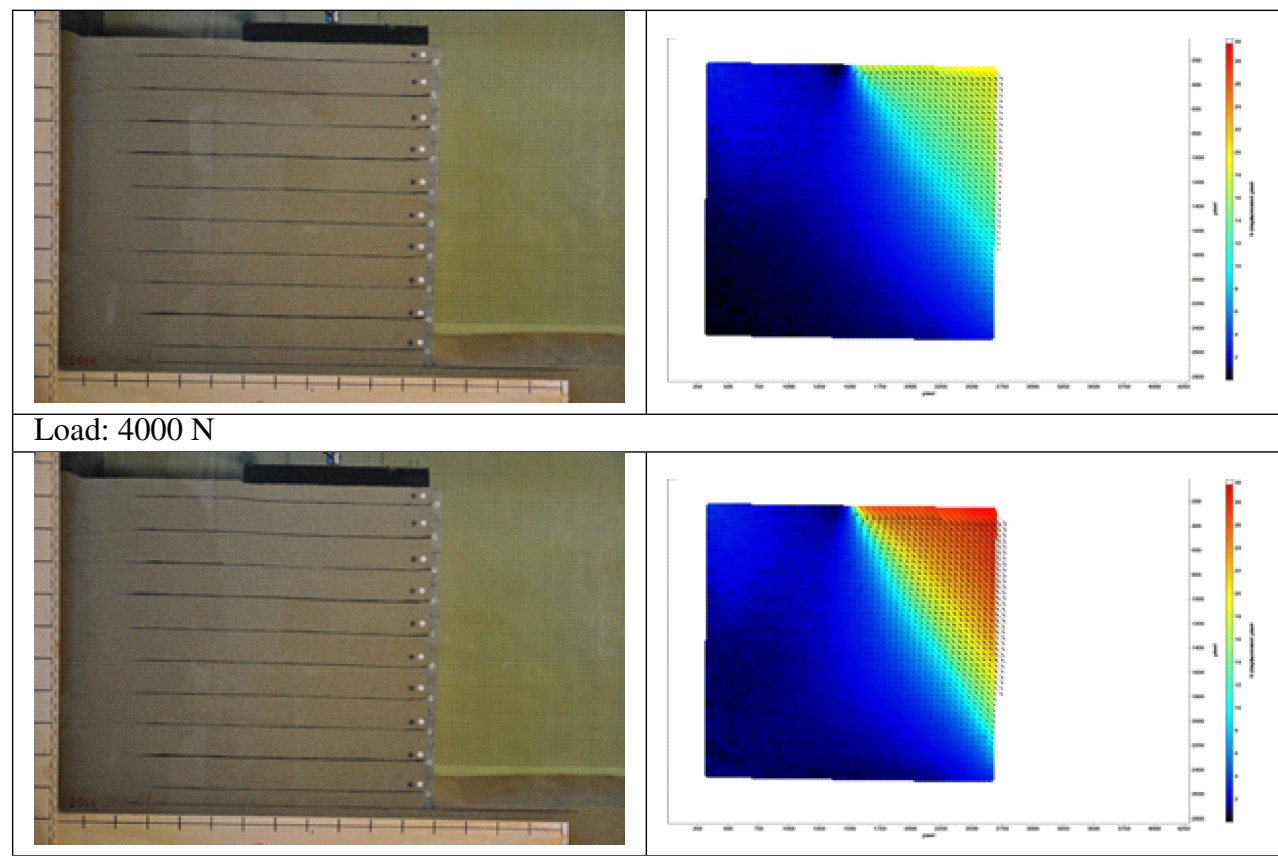

Failure load: $4750 \mathrm{~N}$
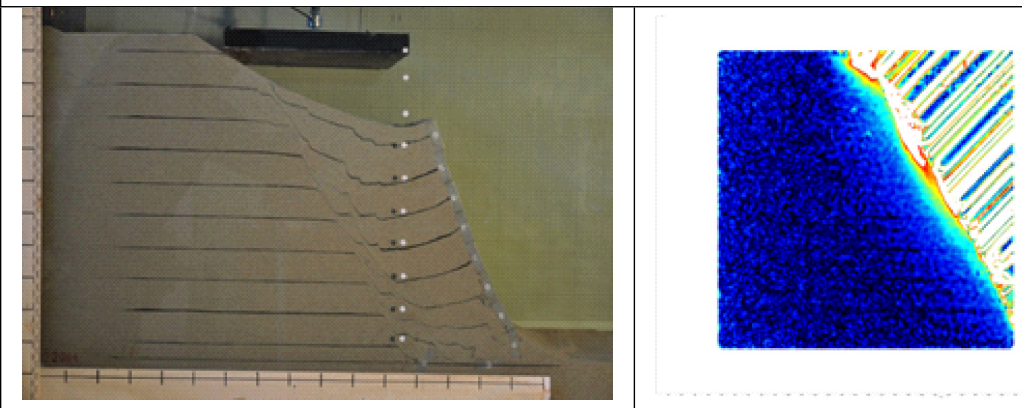

Post failure state

front wall and the value of friction coefficient between the sidewall and the backfill. The analytical solutions have been developed for reinforced soil slopes and retaining walls subjected to self-weight or external loading.

To verify the accuracy of the proposed method of estimation of sidewall friction, the experimental results were compared with theoretical predictions. Two experiments were performed to evaluate the accuracy of the proposed approach: one conducted in the test box with unlubricated sidewalls, and the other performed with sidewalls coated with a lubrication layer. The analytical solutions were close to the experimental results, which indicates that the simple method of sidewall friction estimation proposed in this paper is reliable. 
However, the method described concerns the final stage of loading when the shape of the deformation zone can be easily observed and recorded at a transparent sidewall. To investigate the applicability of the method in stages preceding the initiation of failure, the PIV technique was used for monitoring the evolution of soil particle displacements zone in the model of reinforced soil retaining wall subjected to continuous loading leading to failure. The results obtained show that the deformation zone has been developed beneath footing during the whole loading process, and this zone is similar at all loading stages. Therefore, it can be concluded that the method proposed in this paper can be used to estimate the sidewall friction effect not only under failure conditions, but also under all earlier loading stages.

\section{Acknowledgements}

The author is grateful to Prof. Danuta Leśniewska for her kind help with the PIV analysis.

\section{References}

Bransby P. L., Smith I. (1975) Side Friction in Model Retaining-Wall Experiments, Journal of Geotechnical and Geoenvironmental Engineering, ASCE, 101, GT7, 1975, 615-632, DOI:10.1016/0148-9062(75)90327-7.

Bathurst R. J., Benjamin D. J. (1987) Preliminary Assessment of Sidewall Friction on Large-Scale Wall Models in the RMC Test Facility, The Application of Polymeric Reinforcement in Soil Retaining Structures, NATO Advanced Study Institutes Series, Kluwer Academic Publishers, 1987, 181-192.

Bathurst R. J., Jarrett P. M. (1986) Class A Prediction Exercise for Reinforced Earth Walls, Bulletin No. 1 for NATO Advanced Research Workshop, Application of Polymeric Reinforcementn Soil Retaining Structures, Departments of Civil Engineering, RMC and the University of Strathclyde.

Fang Y., Chen T., Holtz R. D., Lee W. F. (2004) Reduction of boundary friction in model tests, ASTM Geotechnical Testing Journal, 27 (1), 3-13. DOI: 10.1520/GTJ10812.

Jayasree P. K., Rajagopal K., Gnanendran C. T. (2012) Influence of sidewall friction on the results of small-scale laboratory model tests: Numerical Assessment, International Journal of Geomechanics, 12, 119-126. DOI: 10.1061/(ASCE)GM.1943-5622.0000120.

Jewell R. A. (1988) Analysis and Predicted Behaviour for the Royal Military College Trial Wall, [In:] Jarrett P. M., McGown A. (eds.) The Application of Polymeric Reinforcement in Soil Retaining Structures, NATO ASI Series (Series E: Applied Sciences), vol. 147, Springer, Dordrecht. DOI: 10.1007/978-94-009-1405-6_7.

Lambe T. W., Whitman R. V. (1979) Soil Mechanics, SI version, John Wiley and Sons, Inc.

Lesniewska D., Wood D. M. (2009) Observations of stresses and strains in a granular material, Journal of Engineering Mechanics, 135 (9), 1038-1054.

Niedostatkiewicz M., Lesniewska D., Tejchman J. (2011) Experimental analysis of shear zone patterns in cohesionless for earth pressure problems using particle image velocimetry, Strain, 47 (12), $218-231$.

Sawicki A. (2000) Mechanics of Reinforced Soil, A.A. Balkema, Rotterdam/Brookfield, DOI: 10.1201/9781003211303.

Stanier S. A., Blaber J., Take W. A., White D. J. (2016) Improved image-based deformation measurement for geotechnical applications, Can. Geotech. J., 53, 727-739, DOI: 10.1139/cgj-2015-0253. 
Tatsuoka F., Haibara O. (1985) Shear Resistance Between Sand and Smooth or Lubricated Surfaces, Soils and Foundations, 25 (1), 89-98, DOI: 10.3208/sandf1972.25.89.

Tatsuoka F. Molenkamp F., Torii T., Hino T. (1984) Behavior of lubrication layers of platens in element tests, Soils and Foundations, 24 (1), 113-128.

Tsubakihara Y., Kishida H., Nishiyama T. (1993) Friction between Cohesive Soils and Steel, Soils and Foundations, 33 (2), 145-156, DOI: 10.3208/sandf1972.33.2_145.

Tsubakihara Y., Kishida H. (1993) Frictional behaviour between normally consolidated clay and steel by two direct shear type apparatuses, Soils and Foundations, 33 (2), 1-13. DOI: 10.3208/sandf1972.33.2_1.

Vieira C. S., Lopes M. L., Caldeira L. M. (2013) Sand-geotextile interface characterization through monotonic and cyclic direct shear tests, Geosynthetics International, 20 (1), 26-38, DOI: 10.1680/gein.12.00037.

White D. J., Take W. A., Bolton M. D. (2003) Soil deformation measurement using particle image velocimetry (PIV) and photogrammetry, Geotechnique, 53 (7), 619-631, DOI: 10.1680/geot.2003.53.7.619.

Yoshimi Y., Kishida, T. (1981) A Ring Torsion Apparatus for Evaluating Friction Between Soil and Metal Surfaces, Geotechnical Testing Journal, GTJ10783J, 4 (4), 145-152, DOI: 10.1520/GTJ10783J.

Zheng J., Li L., Daviault M. (2021) Experimental Study on the Effectiveness of Lubricants in Reducing Sidewall Friction, International Journal of Geomechanics, 21 (5), 10 pp., DOI: 10.1061/(ASCE)GM.1943-5622.0002003. 